\title{
Genetic Diversity Analysis of Rose (Rosa X hybrida L.) Cultivars based on Morphological Markers
}

\author{
Aparna Veluru* \\ ICAR-Indian Agricultural Research Institute, New Delhi, India \\ *Corresponding author
}

Keywords

Indian rose cultivars, Diversity analysis, Morphological markers, DUS characteristics

Article Info

Accepted:

10 January 2021 Available Online: 10 February 2021

\section{A B S T R A C T}

Characterization and evaluation of genotypes are essential to provide information on the traits of accession assuring its maximum utilization as well as for conservation of germplasm. India adopted a sui generis system in order to offer plant breeders rights for the newly developed varieties and to protect the existing germplasm. In the present study, a total of 109 rose collections were studied for morphological diversity using PPV\&FRA formulated DUS test guidelines. Observations were recorded for a total of 59 morphological descriptors in two consequent years. Considerable amount of variation was noticed for all most all the descriptors, indicating higher diversity among released rose cultivars. The Neibour Joining (NJ) tree separated the 109 cultivars into 10 major clusters based on its morphological similarity. The cultivars are clustered mostly based on its flower colour, flower type and plant growth habit. Majority of the Floribunda and Hybrid Tea cultivars were grouped separately and some of them were intermixed based on the similarities found in few vegetative and reproductive characteristics. The grouping of cultivars in Principal component analysis (PCA) also showed certain degree of resemblance with NJ tree. Present study helps in identification and protection and conservation of Indian rose cultivars, also variability found among cultivars can be usedfor future rose improvement programmes.

\section{Introduction}

Rose (Rosa $\times$ hybrid L.) is one of the most valued ornamental plants with great economic value belongs to family Rosaceae. Genus Rosa contains nearly 200 species and more than 18,000 commercial rose cultivars (Gudin, 2000; Aparna et al., 2019). With the increasing demand for novel rose cultivars in the world flower market, a huge number of varieties are being bred every year with novel flowering and plant traits. Therefore, precise identification and characterization of those cultivars is necessary for variety control, identification, and protection of plant breeder's rights. Plant characterization helps us by providing the detailed description about material, which is vital for its conservation, management, and utilization of the material.

Morphological and physiological traits are commonly used in characterization of plant genetic resources. Though number of tools available to analyse the relationship among 
the cultivars; morphological characterization is found to be key step for studying cultivar description and classification (Panwar et al., 2010; Gaurav et al., 2018; Aparna et al., 2019a). With the emergence of Protection of Plant Varieties and Farmers Rights (PPV\& FRA) 2001 in India, the potential application of the DUS test guidelines to distinguish a candidate variety from the reference material was successfully demonstrated in different (Rose, Chrysanthemum, Bougainvillea, Tube rose) floricultural crops at IARI.

The Division of Floriculture and Landscaping, IARI is one of the designated DUS testing centres for roses and has developed the test guidelines comprising of 62 morphological characters (Prasad et al., 2007). India is native for almost 25 wild species and 600 modern rose cultivars. In the present study we have tried to analyse the genetic diversity and relationship among 109 Indian rose cultivars using morphological data.

\section{Materials and Methods}

Present study was carried out in the research farm of Division of Floricultural and Landscaping, IARI, New Delhi, which is one of the DUS validation centre for Rose approved by PPV\& FRA. The experimental material comprised of 109 Indian bred rose cultivars which are listed in table 1. A total of 59 morphological characters were selected from PPV\&FRA drafted DUS guidelines developed for roses (Table 2). For each cultivar, 10 representative plants were selected for collecting data in two subsequent years. Morphological data was analysed with NTSYS software version 2.2 (Rohlf, 2000). Principal component analysis (PCA) was also done to delineate morphological similarities among studied cultivars using morphological data.

\section{Results and Discussion}

\section{Cluster analysis using Neighbour Joining (NJ) Method}

The NJ dendrogram based on morphological characters divided 109 rose cultivars into 10 major clusters and several sub clusters. Out of 10 major clusters, cluster VI and clusters VIII were exhibited as largest clusters with 27 cultivars each, followed by cluster V and IX with16 and 15 cultivars. Cluster IV, III and IV contains 4 cultivars in each cluster. Cluster I and X consists 3cultivars each and cluster II is smallest of all with 2 cultivars (Fig.1 and Table 1).

Clusters I consist of Hybrid Tea cultivars Madhosh, Pusa Mansij and Sahasradhara, they had more than one colour on its petals. Majority colour of the petal was red purple, red and pink. Secondary and tertiary colours (red purple, red and white) were distributed on the petals as stripes, speckles, and segments in Sahasradhara, Pusa Mansij and Madhosh cultivars, respectively. Cluster II contains two cultivars Madhura and Pusa Manhar belong to Floribunda group having petals with orange and pink blends and secondary colour is distributed at the apex of the petal in both the cultivars. In cluster- III, a violet flower coloured Floribunda cultivar Neelambari was grouped with HT cultivars Dr. M.S. Randhawa, Pusa Sonara and Raja Ram Mohan Rai, they had red purple to apricot blend petal colour with strong anthocyanin colouration in shoot as well as prickles. Six HT cultivars (Mrinalini, Pusa Ajay, Priyadharshini, Pusa Gaurav, Shreyasi and Surekha) grouped together in cluster number IV. Six of them had similar plant growth habits with strong anthocyanin colouration on shoot and prickles. Flowering shoot laterals were present in all the cultivars, flower colour ranges from red-to-red purple with pitcher shaped seed vessel. 
Cluster V divided into two sub-clusters, viz. $\mathrm{Va}(7$ cultivars $)$ and $\mathrm{Vb}(6$ cultivars $)$. First major cluster includes five HT and two Floribunda cultivars, which is further sub divided into two minor clusters with yellow (Ganga, Jawahar and Pusa Pitambar) and white coloured (Mother Teresa, Mridula, Ms. K.B. Sharma, Navneet) flower types. Floribunda cultivar Pusa Pitambar is a resultant of cross between two Floribunda cultivars 'Jantar Mantar $\times$ Banjaran', but it had characteristics (plant height, double flower with dense petal arrangement and absence of flower shoot laterals) similar to Hybrid Tea group. The other Floribunda cultivar Navneet also had some identical characteristics from HT group i.e., plant height and flower size. Second sub-cluster $(\mathrm{Vb})$ again formed two minor clusters. Minor cluster one had three HT varieties (Lalima, Nehru Centenary, Pusa Bahadur), three of them had almost similar morphological characters and bears a large, red to red, purple-coloured flowers with dense petal arrangement. Another minor cluster contains six Floribunda varieties with similar growth characteristics. Three of them (Sabnam, Loree and Himangini) had white coloured flowers and remaining three cultivars (Lahar, Banjaran and Chingari) had flower colours with yellow orange and red blends.

Table.1 List of rose genotypes used for morphological and molecular characterization

\begin{tabular}{|l|l|}
\hline \multicolumn{1}{|c|}{ Population } & \multicolumn{1}{|c|}{ Rose genotypes } \\
\hline Indian & Abhisarika, Anurag, Arjun, ArkaParimala, Aruna, Ashwini, \\
& Bhim, Century Two seedling, Chambe-di-Kali, Chitra, Dil-ki- \\
& Rani, Dr. B.P. Pal, Dr. Benjamin Pal, Dr. Bharat Ram, Dr. M.S. \\
& Randhawa, Dr. R.R. Pal, Dulhan, Eiffel tower × Queen Elizabeth, \\
& Ganga, Golden Afternoon, Haseena, Homage, Jawani, Lalima, \\
& Lal Makhmal, Madhosh, Maharani, Mother Teresa, Mridula, \\
& Mrinalini, Mrs. K. B. Sharma, Nayika, Nehru Centenary, \\
& Nurjahan, Pink Montezuma, Preyasi, Priyadharshini, Pusa Ajay, \\
& Pusa Arun, Pusa Bahadur, Pusa Garima, Pusa Mansij, Pusa Mohit, \\
& Pusa Priya, Pusa Sonara, Raja Ram Mohan Roy, Raja Surendra \\
& Singh of Nalagarh, Rajkumari, Raktagandha, Raktima, Ranjana, \\
& Ratnaar, Sahasradhara, Shanti Pal, Shreyasi, Sir. C. V. Raman, \\
& Soma, Sugandha, Surabhi, Surekha, Surkhab, Jawahar, Shiloz \\
& Mukherjee, Indian Princess, Pusa Gaurav, Pusa Shatabdi, Akash \\
& Sundari, Delhi White Powder Puff, Delhi Pink Powder Puff, \\
& Anitha, Arunima, Banjaran, Chingari, Deepak, Delhi Brightness, \\
& Delhi Princess, Dr. S. S. Bhatnagar, Himangini, Jantar Mantar, \\
& Krishna, Lahar, Loree, Madhura, Manmatha, Manasi, Mohini, \\
& Navneet, Neelambari, Prema, Punchu, Pusa Abhishek, Pusa \\
& Barahmasi, Pusa Komal, Pusa Pitambar, Rupali, Sabnam, \\
Sadabahar, Shola, Sindhoor, Suchitra, Surdas, Suryakiran, \\
Suryodaya, Tarang, Pusa Virangana, Pusa Manhar, Pusa Urmil, \\
Pusa Muskan, Rose Sherbet
\end{tabular}


Table.2 List of descriptors used for morphological characterization

\begin{tabular}{|c|c|c|c|}
\hline S.NO & Characters & & Characters \\
\hline 1 & Plant: Growth type (VG) & 31 & Flower: side view of lower part (VG) \\
\hline 2 & Plant: Growth habit (VG) & 32 & Flower: Fragrance (MS) \\
\hline 3 & Plant: Height $(\mathrm{cm})(\mathrm{MS})$ & 33 & Sepal extensions \\
\hline 4 & $\begin{array}{l}\text { Young shoot: Anthocyanin colouration } \\
\text { (VG) }\end{array}$ & 34 & Petal: Reflexing of petals one by one (VG) \\
\hline 5 & $\begin{array}{l}\text { Young shoot: Intensity of Anthocyanin } \\
\text { colouration (VG) }\end{array}$ & 35 & Petal shape (VG) \\
\hline 6 & Stem: Number of prickles (VG) & 36 & Petal incisions (VG) \\
\hline 7 & Prickles: Predominant colour (VG) & 37 & Petal: Reflexing of margin (VG) \\
\hline 8 & Prickle: Shape of lower side (VS) & 38 & Petal: Undulation of margin (VG) \\
\hline 9 & Leaf: size (MS) & 39 & Petal: length (MS) \\
\hline 10 & $\begin{array}{l}\text { Leaf: intensity of green colour on upper } \\
\text { side (VG) }\end{array}$ & 40 & Petal: Width (MS) \\
\hline 11 & Leaf: Anthocyanin colouration (VG) & 41 & Petal: Number of colours on inner side (VG) \\
\hline 12 & Leaf: Glossiness of upper side (VG) & 42 & $\begin{array}{l}\text { Varieties with one colour on inner side of petal: Intensity } \\
\text { of colour excluding basal the spot }(\mathrm{VG})\end{array}$ \\
\hline 13 & Leaflet: Undulations of margin (VG) & 43 & Petal: Colour of the majority portion of petal (VG) \\
\hline 14 & Leaflet: Serration of margin (VG) & 44 & $\begin{array}{l}\text { Varieties with two or more colours on inner side of petal: } \\
\text { Secondary colour of petal (VG) }\end{array}$ \\
\hline 15 & Terminal leaflet: Shape of blade (MS) & 45 & $\begin{array}{l}\text { Varieties with two or more colours on inner side of petal: } \\
\text { Tertiary colour of petal (VG) }\end{array}$ \\
\hline 16 & $\begin{array}{l}\text { Terminal leaflet: Shape of base of blade } \\
\text { (MS) }\end{array}$ & 46 & $\begin{array}{l}\text { Varieties with two or more colours on inner side of petal: } \\
\text { Petal distribution of secondary colour on inner side (VG) }\end{array}$ \\
\hline 17 & $\begin{array}{l}\text { Terminal leaflet: Shape of apex of blade } \\
\text { (VG) }\end{array}$ & 47 & $\begin{array}{l}\text { Varieties with two or more colours on inner side of petal: } \\
\text { Petal distribution of tertiary colour on inner side (VG) }\end{array}$ \\
\hline 18 & Flowering shoot: Flowering laterals (VS) & 48 & Petal: Spot at base of inner side (VG) \\
\hline 19 & $\begin{array}{l}\text { Flowering shoot: number of flowering } \\
\text { laterals (MG) }\end{array}$ & 49 & Petal: Size of spot at base of inner side (VG) \\
\hline 20 & $\begin{array}{l}\text { Flowering shoot: Number of Flowers } \\
\text { (MG) }\end{array}$ & 50 & Petal: Colour of spot at base of inner side (VG) \\
\hline 21 & $\begin{array}{l}\text { Flowering shoot: number of flowers per } \\
\text { lateral (MG) }\end{array}$ & 51 & Petal: Colour of spot at base of outer side (VG) \\
\hline 22 & $\begin{array}{l}\text { Flower bud: Shape of Longitudinal Section } \\
\text { (VG) }\end{array}$ & 52 & Petal: Main colour on outer side (VG) \\
\hline 23 & Flower: Type (VG) & 53 & Petal spot at base of outer side (VG) \\
\hline 24 & Flower: Number of petals (MS) & 54 & Petal: size of spot at base of outer side (VG) \\
\hline 25 & Flower: Colour group (VG) & 55 & Outer stamen: Predominant colour of the filament (VG) \\
\hline 26 & Flower: Diameter (MS) & 56 & Seed vessel: Size (VG) \\
\hline 27 & Flower: Colour of the centre (VG) & 57 & Hip: shape of longitudinal section (VG) \\
\hline 28 & Flower: Density of petals (MG) & 58 & Flower: length of pedicel (MS) \\
\hline 29 & Flower shape: View from above (VG) & 59 & Flower: Venation of Petals (VG) \\
\hline 30 & Flower: Side view of upper part (VG) & & \\
\hline
\end{tabular}


Fig.1 NJ clustering of rose cultivars based on morphological data

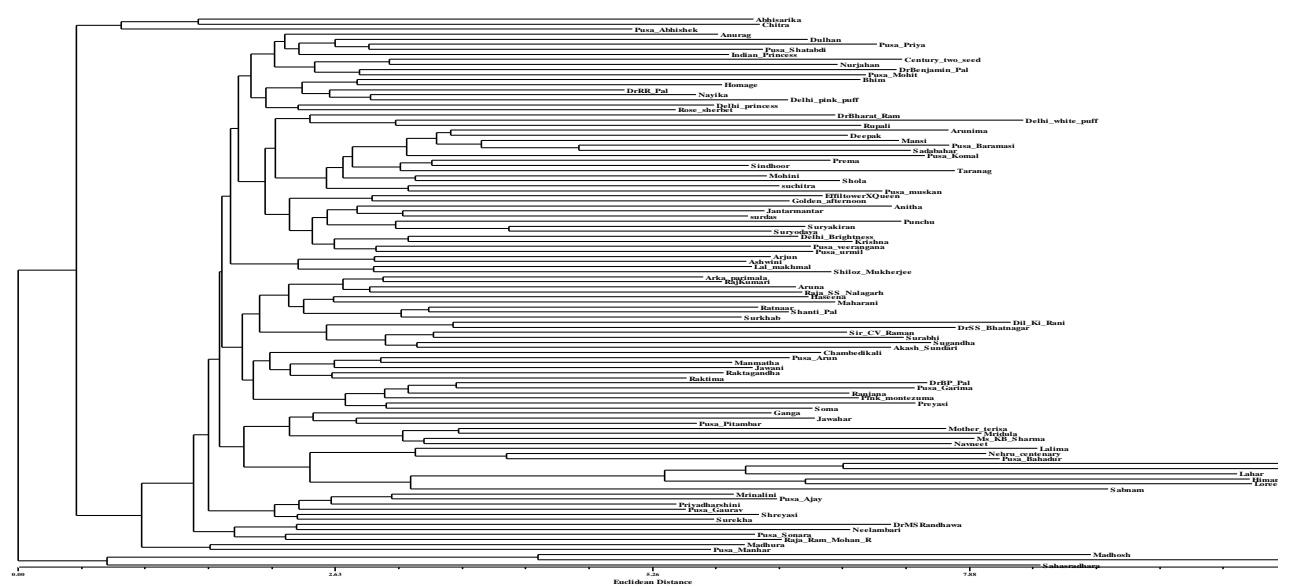

Fig.2 PCA clustering of rose cultivars based on characterized morphological data

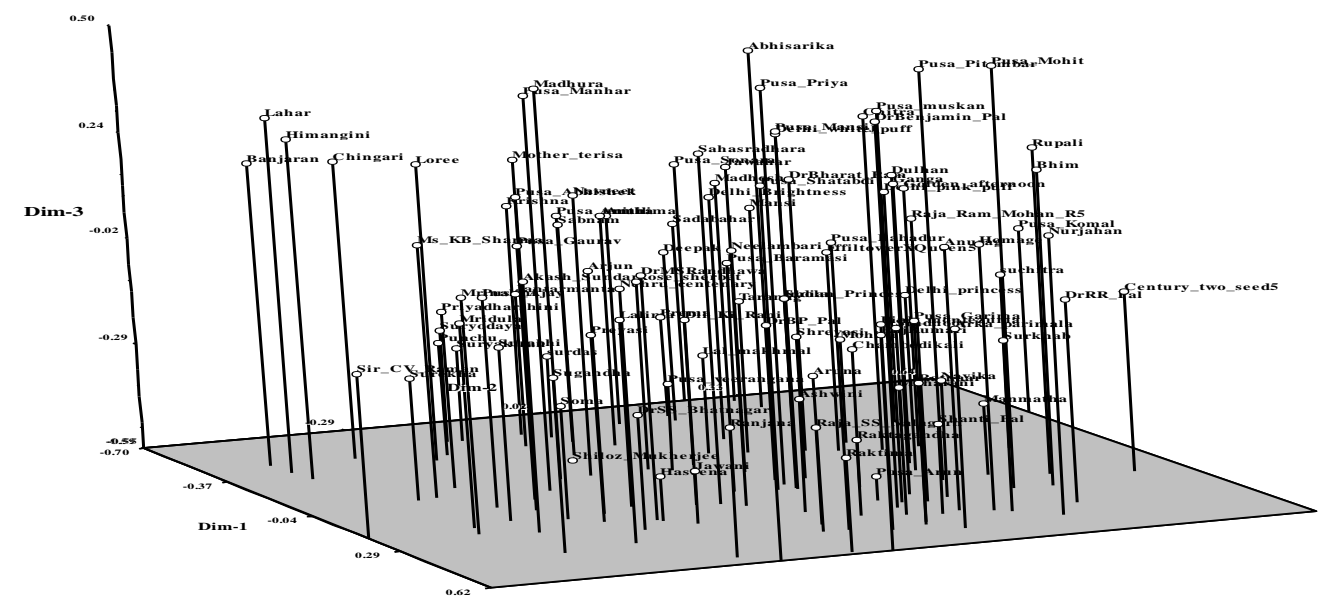

Cluster VI is one of the largest clusters contains two major sub-clusters (VIa and VIb). Sub-cluster Via consists of cultivars which bears red to red, purple-coloured flowers with semi double or double flower type having medium to strong flower fragrance, flowers are almost round to star in shape with strong petal undulation. Anthocyanin pigmentation was present on shoots and prickles in almost all the cultivars. Sub cluster VIa consists total 15 cultivars. of which, two of them belongs to Floribunda (Dr.S.S.Bhatnagar, Akash Sundari) group. These two cultivars have shared some identical characteristics with HT cultivars like plant growth type and presence of double flowers (Akash Sundari). Similarly, some of the HT cultivars had characters akin to Floribunda cultivars viz. presence of flower shoot laterals (Sir C.V. Raman, Sugandha), semi double flowers with loose petal arrangement (Dil-ki-Rani) and bed kind of growth with short plant height (Shanti Pal, Dil-ki-Rani, Maharani and Aruna). Sub cluster VIb had 12 cultivars (11 HT and one Floribunda). All of them had shrubby growth type with semi- upright to upright growth habit and plant height ranges from medium to tall (including floribunda cultivar 'Manmatha'). Red to red purple coloured, 
large size and round shaped double flowers with medium to dense petal arrangement was observed in this cluster (Including Floribunda cultivar Manmatha). Flower fragrance was observed in almost all except cultivars Pusa Arun and Manmatha. Yong shoots anthocyanin colouration was present in all cultivars and intensity varies from weak (Manmatha, Pusa Garima), medium (Ranjana, Raktagandha) and strong. Prickles are many with deep concave to concave in nature having light yellowish to brownish colour. Flower shoot laterals were seen only in HT cultivar Soma. Cultivars of this cluster had different coloured outer stamens light yellow (Jawani), medium yellow (Manmatha, Preyasi), orange (Pusa Arun, Raktagandha), pink (Chambe-di-Kali, Raktima, Dr. B.P.Pal, Pusa Garima, Pink Montezuma, Soma), red (Ranjana). Seed vessel is very small to medium in size having pitcher shape.But cultivars Pusa Garima and Ranjana had funnel shaped seed vessel. Cluster number VII had four Hybrid Tea cultivars, having similar morphological features such as anthocyanin pigmentation on leaf and young shoots, prickle number, colour and shape, leaf glossiness, flower shape number of petals and seed vessel size and shape.

Two sub clusters and four mini clusters with a total of 27 cultivars observed in cluster VIII. And majority of them belongs to Floribunda group (24 floribunda and $3 \mathrm{HT}$ ). Two mini clusters (VIIIb and VIIId) consist cultivars only from Floribunda group and each of them had 13 and 10 cultivars sequentially. Most of the cultivars from this mini clusters had bed type of plant growth with short plant stature having flower shoot laterals. Minicluster (VIIIc) had two HT cultivars i.e., Golden Afternoon and a seedling from the cross 'Eiffel Tower $\times$ Queen Elizabeth', these two cultivars had semi-double flowers with medium number of petals like other Floribunda cultivars in this cluster. The other mini cluster VIIIa had two Floribunda cultivars along with HT cultivar Dr. Bharat Ram, this cultivar had all the characters from HT group except flower type and presence of flower shoot laterals.

In cluster number IX, a total of 15 cultivars are present and most of them had medium to tall plant height with red-to-red purple coloured, double type, fragrant flowers. Three cultivars (Abhisarika, Chitra and Pusa Abhishek) with blended coloured flowers were grouped separately in cluster no $\mathrm{X}$ and they had intermediate (Chitra) to semi-upright growth habit with semi-double to double (Chitra) flowers, secondary colour is distributed as speckles on the petals.

\section{Cluster analysis using Principal Component Analysis (PCA)}

Morphological data was subjected to Principal Component Analysis and PCA scatter plot was constructed (Fig.2) The PCA scatter plot specifies the spatial representations of genetic distances among cultivars. First three PCA values accounts for 11.2, 6.9 and 5.5\% variation respectively were utilized to compute PCA scatter plot. Total eight clusters were formed; Separation was majorly based on flower type. Most of the Floribunda and Hybrid Tea cultivars were grouped separately and some of them were intermixed.

In conclusion the aesthetic value of rose comes from the diverse morphological characters and the study has reported presence of significant variation for all the characters studied. The present study classified the rose cultivars into character-based groups and the helps to identify the reference genotype which can be deployed for characterization of rose cultivars across locations and years in future. This quantification of existing genetic variation and identification of cultivar for each economic character and grouping the 
popular cultivars based on genetic divergence will help breeders to select an appropriate cultivar and utilize them for future rose improvement through systematic and scientific breeding approaches.

\section{References}

Aparna, V., Bhat, K. V., Janakiram T., Prasad, K.V., Raju, D.V.S and Bharadwaj, C., Gayacharan, Singh, K. P, Namita and Panwar, S. 2019. Understanding genetic diversity, structure and population differentiation in selected wild species and cultivated Indian and exotic rose varieties based on microsatellite allele frequencies. Indian J Genet. 79(3): 583-593.

Aparna, V., Bhat, K. V., Janakiram, T., Prasad, K. V., Raju, D. V. S, Panwar, S., Namita, Singh, K. P. 2019a. Assessment of genetic diversity and population structure of fragrant rose (Rosa $\times$ hybrida L.) cultivars using microsatellite markers. Indian J Agril
Sci. 89(11): 1964-70.

Gaurav, A. K, Namita, Raju, D. V. S, Singh, M., Panwar, S. and Vani, K. G. 2018. Morphological Assessment of Rose species and variants using multivariate analysis. Int. J. Chem. Stu.6(2): 3277 3282.

Gudin, S.2000. Rose: genetics and breeding. Plant BreedRev.17:59-189

Panwar, S., Singh, K. P., Namita, and Sonah, H. 2010. Genetic divergence analysis in rose (Rosa $\times$ hybrida L.) using morphological markers. J Ornamental Hortic.13(2): 122-126

Prasad, K.V., Kumar, G., Kumar, S., Singh, O., and Kumari, G. 2007. DUS testing of chrysanthemum: A prerequisite for offering plant breeder's right. A poster presented in 2nd Indian Horticulture Congress, April 17-21, Barapani, Meghalaya.

Rohlf, F. J. 2000. NTSYSpc: Numerical Taxonomy and Multivariate Analysis System. Version 2.02. Exeter Software, Setauket, New York.

\section{How to cite this article:}

Aparna Veluru. 2021. Genetic Diversity Analysis of Rose (Rosa X hybrida L.) Cultivars based on Morphological Markers. Int.J.Curr.Microbiol.App.Sci. 10(02): 1349-1355.

doi: https://doi.org/10.20546/ijcmas.2021.1002.160 